\title{
THREE QUESTIONS CONCERNING REID'S MORAL EPISTMEOLOGY
}

\author{
Phillip Zema \\ Dr. Peter Markie, Dissertation Supervisor \\ Dr. Marina Folescu, Dissertation Co-advisor
}

\begin{abstract}
I argue for what I think is the most plausible interpretation of Reid's moral epistemology; in doing so, this interpretation answers three broad questions concerning the nature of Reid's moral philosophy: (1) What is the best way to interpret Reid's account of the moral sense, the faculty by which we make moral judgments and obtain moral knowledge? (2) What is the nature of moral reality for Reid? (3) How does the moral sense provide one with knowledge of moral reality? In addition to answering these questions, I address some objections one might raise against my interpretation and Reid's moral philosophy in general. While I do not argue for the soundness of Reid's positions, I aim to put forth an interpretation that accurately reflects what I think Reid intends to claim as well as provide what I think makes his positions the most philosophically plausible.
\end{abstract}

